is an example).

If, on the other hand, 'human mind' is not restricted to adulthood, then it might be thought that claiming an important role for developmental study is little more than a truism. But this neglects the fact that influential theories in contemporary cognitive science have been elaborated as if development did not exist. At its most simplistic, this has involved the writing-off of ontogenetic processes by labelling certain cognitive systems 'innate', a term abandoned 20 years ago by many workers in the subject that had earlier spawned it, development ethology.

But the mind does develop: and to me the success of this book lies not so much in the author's ambition of demonstrating the relevance of development for understanding any mental end-state, but rather in her impressive developmental analysis per se, which deserves wide readership by both developmentalists and nondevelopmentalists who need an overview of the state of the art. Clearly and comprehensively, Karmiloff-Smith shows the highly structured ways in which different representational processes emerge from infancy onwards. It is the totality of these structures that should surely constitute the subject matter of cognitive science.

Successive chapters deal with several principal areas of knowledge, examining the child in turn as linguist, physicist, mathematician, psychologist and notator. In themselves these offer excellent, up-to-date, but fairly concise reviews of current knowledge in each field. Repeatedly one finds explications of difficult concepts, such as the propositional attitudes underlying theory of mind, that are among the clearest available.

But the author goes much further than this, offering a sophisticated model of cognitive change that distinguishes four principal representational formats (in place of the conventional implicitexplicit dichotomy), proceeding from behavioural mastery to metalinguistic awareness. These are not stages in the Piagetian sense, but rather sequential phases of representational redescription that can recur at different ages in different domains. Karmiloff-Smith takes us indeed far beyond (and nicely between) two positions: the Piagetian notion of development as one of several generalized intellectual transitions, and the notion of major cognitive systems, such as theory of mind, as innate modules. Increasingly it looks as if beyond and between these is the place we need to be.

Andrew Whiten is in the Department of Psychology, University of St Andrews, St Andrews, Fife KY16 9JU, UK.

\section{Pain relief}

\section{Gerald Zernig}

Forschen auf Deutsch: der Machiavell für Forscher - und solche die es noch werden wollen*. By Siegfried Bär, with cartoons by Irena Volpi. Harri Deutsch, Frankfurt: 1992. Pp. 125. DM20 (pbk).

You crawl home after one of those days in the lab. Your graduate student has wasted the whole digitonin batch. The manuscript that you have slaved over for the past year has been rejected - but then again, so has your grant application. You are dangerously close to the end of your contract, a fact that has just today been brought to your attention (again!) by your supervisor. To round things up, you had to spend the past hour convincing the usual salesman that you really didn't need a third centrifuge, much less could afford one. You are in terrible need of something, someone to soothe your soul.

Here it is! Written by a postdoc, the same downtrodden academic creature as yourself, this guide in German offers a wildly biased, cynical view of academic life. You feel immediately drawn to the slashing description of all that oppresses you, your neck aches from nodding in bitter appreciation, sometimes you find yourself rolling on the floor with laughter. You have found a voice, someone exposing all the injustices that have befallen you. You cheer, you agree wholeheartedly, and you quickly skip those pages where the author offers his own ambitious advice for solving your problems (after all, you don't want to spoil that sweet feeling of complete harmony with the author).

Then, after a while, with composure regained, you are able to take a look at yourself, your own failings and shortcomings, your own efforts that, this very evening, look so hopeless to you. So many refreshing passages convince you that you are not alone. For example:

Usually, the researcher reads only articles of his very own field in their entirety. Nevertheless he spends a considerable part of his time copying papers which, mostly unread, are stacked or filed. For our time-pressed researcher, copying represents spiritual ownership, an act taking on the importance of a ritual that replaces the tedious process of actually reading the paper. Copying soothes the researcher and blesses him with inner peace and the feeling not to have missed an important bit of information.

There are lots of cartoons, ideally suited for the department coffee room, depicting, for example, the Measure-

*'Researching in German: The Machiavelli for scientists and those who still want to become one'. ments Flunky (his head "contains raisins in a cake mix of little material expectations, ambition and naïveté") or a chart on Academic Metabolism (with the inevitable "USA shunt"). There are interesting bits of information snatched from Nature and Science on science politics: 20 per cent of all biochemical or molecular biology articles - or 40 per cent of all medical papers, for that matter - are never cited. And how about this: in 1982, the average German research paper (which cost the taxpayer $\$ 188,570$ ) was cited only 0.85 times, whereas the average British one could boast an equally meagre 0.96 citations (while, admittedly, costing the UK citizen only $\$ 81,260)$. Sobering facts for all, whether graduates, postdocs, research group leaders, chairmen, deans or government science administrators.

This is a book that you will want to give your child to prevent it from foolishly entering academic science as you yourself did. And it is just the book you need to hang on to until you are rewarded, again, with that exhilarating feeling that, after all, science is the "most exciting thing you can do with your pants on", as you will hear - and wholeheartedly agree with - during the late hours of the banquet of your next congress, when all will have ended well.

Gerald Zernig is in the Department of Pharmacology, University of Michigan Medical School, 6322 Medical Science Building I, Ann Arbor, Michigan 48109. 0626, USA.

\section{New Journals Issue}

This year, Nature's annual new journals review supplement will appear in the issue of 7 October. Publishers and learned societies are invited to submit journals for review, taking note of the following criteria: - Journals that first appeared during or after June 1991 and issued at least four separate numbers by the end of April 1993 will be considered.

- Journals covering any aspect of science are eligible, although those dealing with clinical medicine, engineering and pure mathematics are excluded, as are publications of abstracts.

- Frequency of publication must be at least three times a year. The main language used must be English. Translation journals in English are, of course, eligible.

Deadline for submission is the end of May.

When submitting journals for review, please send at least four different issues (the first, the most recent and any two others) of each title, together with full details of subscription rates (personal and institutional) and frequency of publication, to: Peter Tallack, Nature, 4 Little Essex Street, London WC2R 3LF, UK. For further information please telephone Peter Tallack on 071-836-6633 (011-44-71-836-6633 from the United States), extension 2414 